\title{
Apresentação: Antropologia e Crítica Pós-Colonial
}

\author{
Bruno Reinhardt ${ }^{1}$ \\ Universidade Federal de Santa Catarina, Florianópolis, Santa Catarina, Brasil \\ E-mail: bmnreinhardt@gmail.com

\section{Letícia Cesarino ${ }^{2}$} \\ Universidade Federal de Santa Catarina, Florianópolis, Santa Catarina, Brasil \\ E-mail: leticia.cesarino@ufsc.br
}



necessidade evocada por Talal Asad (neste volume) de lembrar que
“a antropologia não apenas apreende o mundo em que ela está inserida, mas que o mundo também determina como a antropologia irá apreendê-lo" pode soar trivial. No entanto, em 1973, quando Anthropology and the Colonial Encounter foi publicado, a tese de que a antropologia emergiu no bojo do projeto imperial europeu e que esse fato teria implicações longevas em como ela constrói seu objeto de estudos soava não apenas contraintuitiva, mas, para muitos, abertamente ofensiva. Apesar de, na mesma ocasião, Asad (neste volume) ter declarado que considera "[...] um erro ver a antropologia social produzida durante a era colonial primariamente como um suporte para a administração colonial, ou como um simples reflexo da ideologia colonial [...]" - defendendo, portanto, uma abordagem mais complexa para a relação entre poder, representação e intervenção - foi exatamente da primeira forma que seu projeto foi recebido pela comunidade antropológica da época (Loizos, 1977). Não por acaso, as respostas imediatas suscitadas por este livro foram pouco estimulantes intelectualmente (Pels; Salemink, 1994), já que majoritariamente defensivas (Gluckman, 1974), negando-se a engajar com o debate proposto por Asad e corroborando, assim, a sua urgência ${ }^{3}$.

Conversas mais elaboradas acerca da "colonialidade" do saberpoder Ocidental, ou do fato de que "[...] o sistema mundial moderno tende a ser concebido através do seu próprio imaginário, e não do imaginário da diferença que ele produz [...]" (Mignolo, 2001, p. 22), tiveram que esperar algum tempo para florescer de maneira robusta entre antropólogos. Hoje, contudo, se tornaram incontornáveis. Pode-se de fato afirmar que a antropologia contemporânea é a mais reflexiva das ciências sociais, tendo transitado de forma tensa, mas produtiva, de uma 
disposição defensiva com relação à sua autoridade científica e fronteiras disciplinares para um engajamento com a autocrítica enquanto recurso epistemológico e político intrínseco à sua tradição disciplinar. Essa transformação paradigmática na percepção e apercepção antropológicas parece indicar uma quebra derradeira com o "sono dogmático" de décadas anteriores ${ }^{4}$.

Primeiro, a antropologia viveu uma visível transformação em sua consciência história, refletida de forma mais explícita no subcampo da história da antropologia, através da rejeição de modelos historicistas clássicos preocupados exclusivamente em “[...] entender o passado por si mesmo" (Stocking Jr., 1968, p. 9). Publicações como a série History of Anthropology, editada por George Stocking Jr. a partir de 1968, ou O Tempo e o Outro, de Johannes Fabian [1983] (2013), introduziram modelos mais próximos de uma "história do presente", cuja finalidade seria não celebrar o cânone por meio de narrativas progressistas sobre seu amadurecimento científico, mas desvelar as dinâmicas condições histórico-políticas de seu imaginário e técnicas representativas - em suma, as historicidades do empreendimento antropológico. A antropologia histórica do sistema capitalista mundial (Wolf, 1982; Mintz, 1985 ) e, principalmente, a emergência do subcampo da antropologia do colonialismo nos anos 1990, que incluiu o estudo detalhado de dispositivos coloniais de governo da diferença familiares ao métier antropológico como "raça", "cultura", "tribo", "nação", "sociedade", "religião", etc., foram igualmente centrais neste processo (Comaroff; Comaroff, 1991; 1997; Dirk, 1992; Pels, 1997; Reinhardt, 2014).

Em segundo lugar, antropólogos passaram a engajar de forma mais reflexiva com os dois pilares metodológicos que sustentam a sua autoridade científica: o trabalho de campo e a escrita etnográfica (Clifford; Marcus, 2016) [1986] $]^{5}$. Não obstante seus deslizes narcisistas (Viveiros de Castro, 2015), a chamada virada pós-moderna estimulou o cultivo de um salutar ethos experimentalista e autocrítico na disciplina, além de uma revisão global de seus propósitos: da descrição científica de culturas não Ocidentais para a produção colaborativa de críticas culturais (Marcus; Fischer, 1986). A antropologia da antropologia tornava-se, assim, uma modalidade de antropologia da modernidade entre outras (Peirano, 1998; Rabinow, 1999). 
Em terceiro lugar, a antropologia passou por mudanças igualmente importantes de ordem institucional. A multiplicação de departamentos para além dos centros euro-norte-americanos tem suscitado, desde os anos 1980, debates de ordem geopolítica sobre a formação do campo disciplinar em termos de processos de empire- e state-building (Gerholm; Ulf Hannerz, 1982; Peirano, 1991). Antes colocada em termos de antropologias "centrais" e "periféricas" (Stocking Jr., 1982), essa tematização abre caminho para projetos mais simétricos ancorados em "antropologias mundiais" (Ribeiro; Escobar, 2006), que tematizam as desigualdades que caracterizam a divisão global do trabalho antropológico. Esse crescente afinamento da atenção para a natureza inerentemente situada (Haraway, 1988) da chamada "perspectiva antropológica", cuja homogeneidade científica mascararia privilégios e disposições particulares, vai além da nacionalidade, e tem incluído marcadores de diferença que operam em outras escalas concatenadas, como raça, gênero, classe e etnicidade (Segato, 2012a).

Parte desse amadurecimento autocrítico da antropologia contemporânea pode ser atribuído a diálogos interdisciplinares com a crítica pós-colonial, que desponta de maneira mais sistemática na academia a partir de 1978, com a publicação do Orientalismo de Edward Said, e a subsequente emergência dos estudos subalternos na Índia e sua diáspora. Sublinhamos o "mais sistemática" porque muitos dos seus temas e debates foram prefigurados já na primeira metade do século 20 no campo da literatura pós-colonial (Achebe, 1988) e por autores diretamente envolvidos nas lutas pela descolonização, como Aimé Césaire, Franz Fanon, Albert Memmi, entre muitos outros. David Scott (1999), no entanto, destaca uma importante diferença entre esses dois conjuntos de intelectuais, cujas obras, apesar de aparentadas, formulariam sua crítica ao colonialismo através de protocolos alternativos.

O momento que Scott denomina anticolonial foi formado no bojo das lutas contra o colonialismo na África, Ásia, Oriente Médio e Caribe, cujos ideais libertários adquiriram uma dimensão transnacional com a Conferência de Bandung em 1955. O poder colonial era abordado, sobretudo, como uma força extrativa e coercitiva de natureza social, 
econômica e política, cuja força continha a autodeterminação e a prosperidade dos povos colonizados. Sob uma ótica anticolonial,

[...] o problema da relação entre colonialismo e conhecimento consistia no problema da discrepância entre as (des) representações europeias e a realidade do colonizado: o problema, em outras palavras, da inautenticidade do conhecimento colonial. (Scott, 1999, p. 11; Fanon, [1952] 2008; Memmi [1957] 1965)

A resposta foi dada, sobretudo, no campo político, articulando representação e realidade através da luta pela soberania e autodeterminação.

Os protocolos do discurso anticolonial são exemplificados pelo argumento de Frantz Fanon [1961] (1979, p. 25, 26) em Os Condenados da Terra sobre a inevitabilidade da violência para a descolonização, entendida como um processo necessariamente revolucionário de "[...] substituição de uma espécie de homens por outras espécie de homens", uma "substituição total", um "programa de desordem absoluta". É parte desse contexto a imagem da antropologia como "serva do colonialismo", status similar ao reservado por Fanon às elites nacionalistas reformistas dos países colonizados (entre as quais ele destacou as da América Latina). Essa alcunha é epitomizada pelo famoso quadro que enfeitava o escritório de Kwame Nkrumah, líder da independência e primeiro presidente de Gana, que o representava lutando contra os grilhões do colonialismo britânico sob os olhares plácidos de três homens brancos que simbolizavam o regime colonial: um capitalista portando uma mala, um missionário portando uma Bíblia, e um antropólogo portando a sua cópia de African Political Systems (Kuper, 1985, p. 94).

Scott caracteriza o momento pós-colonial como um modo alternativo de problematização: uma guinda da demanda por representação política em direção à descolonização da própria representação. Isso acontece já em um contexto pós-independência, e em meio a um desencantamento geral com a ideia de que a soberania política seria a panaceia para todos os males do colonialismo.

[...] quando, em suma, o terceiro mundismo liberacionista de Bandung estava em declínio, um novo campo de discurso político-cognitivo emergiu. Localizado geograficamente 
e institucionalmente na academia do Atlântico Norte (particularmente nos Estados Unidos e na Inglaterra) e animado frequentemente por intelectuais diaspóricos ou em exílio originados do Terceiro Mundo, esse campo de discurso teórico preocupava-se com a reproblematização da compreensão do colonialismo formulada pelas teorias nacionalistas (liberais e marxistas) das lutas anticoloniais. Esse novo discurso teórico interessava-se especialmente por certos pressupostos dos nacionalistas anticoloniais quanto à cultura, classe, subjetividade, história, conhecimento, etc. Este é o momento - e o espaço-problema político e teórico - da pós-colonialidade. (Scott, 1998, p. 11)

O momento pós-colonial nasce, em suma, da "persistência do colonial no coração da soberania" (Scott, 1998, p. 14), e seus intelectuais preocuparam-se, sobretudo, com a descolonização da representação Ocidental do não Ocidental, incluindo seus impactos formativos na apercepção deste último. Essa perspectiva é acessada de forma exemplar através das diversas definições de "Orientalismo" oferecidas por Said em seu livro [1978] (2006, p. 2, 4, 4, 22, 127): "uma tradição acadêmica", ou seja, uma rede institucional produtora de experts sobre o "Oriente"; “[...] um estilo de pensamento fundado na distinção ontológica e epistemológica entre o Oriente e o Ocidente [...]", cujo modelo dicotômico influenciou tanto o senso comum europeu quanto sua política imperial; uma forma europeia de "se aproximar e se distanciar do Oriente" que teria impacto formativo em ambos; e uma "tecnologia de poder" cuja finalidade seria legitimar a dominação e reestruturação do Oriente à luz de representações autorizadas por esta ciência dos colonizados.

Assim como o trabalho de Asad (1973b) - que antecipa e amplia uma série de pontos levantados por Said com relação ao Orientalismo ao colocá-lo em paralelo com a antropologia funcionalista na África essa obra foi recebida por antropólogos de maneira defensiva (Gellner 1980), mas logo gerou uma série debates produtivos (Clifford, 1980). Sua abordagem foucaultiana pioneira para o colonialismo como um corpo de "saberes-poderes", focada na hegemonia enquanto "discurso" materialmente inscrito, foi desde então refinada e estendida para uma série de outros campos do conhecimento e áreas geográficas: os estudos 
literários britânicos na administração colonial na Índia (Viswanathan, 1989), a matemática no aparato educacional europeu na África (Bishop, 1990), a ciência política no processo imperial de "modernização" do Egito (Mitchell, 1991), o indigenismo e a política da etnicidade no Brasil (Ramos, 1998). Para Mudimbe (1988), por exemplo, a "estrutura colonizadora" na África foi multimodal, operando tanto pelo governo exógeno das populações africanas com a finalidade de extrair trabalho e recursos quanto como uma condição de inteligibilidade para a própria "ideia de África", que teria ressonâncias pós-coloniais concretas. Sob essa ótica, a africanização do estado não implicaria diretamente em sua descolonização (Mandani, 1996); o problema da herança colonial torna-se assim mais sub-reptício, logo irredutível à noção de "neocolonialismo" utilizada pelos autores anticoloniais.

Para a crítica pós-colonial, o poder colonial se desenrola e se reproduz, sobretudo, na forma de arquivos e estratégias descoladas da mera intencionalidade individual, o que ajudou a refinar a autocrítica antropológica sobre a sua atividade de objetificação do Outro. Um dos problemas-chave legados à antropologia por essa tradição foi o da agência histórica ou "voz subalterna" (Carvalho, 2001). Em um ensaio influente, Gayatri Spivak (1985) discute a "violência epistêmica" do projeto imperialista e inspeciona a ausência de um "fora-texto" extracolonial, no sentido de recursos discursivos, éticos e políticos aptos a contraefetuar a diferença colonial a partir de um ponto de vantagem exógeno. Revisitando o debate sobre o sati na Índia, Spivak demonstra como o projeto dos estudos subalternos de reescrever a história deste país a partir dos camponeses e outras classes populares, ou o projeto feminista de reclamar a "experiência feminina" subalterna, inevitavelmente se veem entrelaçados nas redes do arquivo colonial que eles mesmos pretendem subverter.

O argumento de Spivak sobre a mutabilidade do sujeito subalterno parece ser o reflexo melancólico da guinada pós-utópica que distingue a crítica pós-colonial da anticolonial. De fato, esse é um dos motivos que embasam a tendência de autores latino-americanos (cujos estadosnação, gestados em períodos anteriores do imperialismo europeu, não passaram pela "ressaca pós-Bandung" apontada por Scott) de qualificar 
seu projeto como decolonial, e assim se distanciar deste cânone (Escobar, 2007). Noções avançadas por esses autores que já extrapolaram seu círculo, como a "colonialidade do poder" de Aníbal Quijano (2005) e a "diferença colonial" e o "pensamento de fronteira" de Walter Mignolo (2000), pretendem conformar um vocabulário mais adequado à condição pós-colonial em uma parte do mundo cujo processo colonizador original foi contemporâneo à própria emergência da modernidade europeia, e que tem se desenvolvido historicamente, desde então, dentro - porém nas margens - da esfera geopolítica, econômica e cultural do Ocidente.

Outras autoras que se debruçaram sobre a espinhosa questão do sati, como Lata Mani (1987), ou sobre o problema da diferença de gênero a partir de uma perspectiva pós-colonial, como Chandra Mohanty (1984) e Saba Mahmood (2005), de fato conseguem articular a questão da "voz" da mulher subalterna de maneira mais propositiva. Independentemente de como nos posicionamos nesse campo, vale lembrar que todos esses autores reconhecem as dimensões coercitivas e construtivas do poder colonial destacadas por Said e Spivak, evitando equacionar agência histórica com uma simples presença-a-si coletiva de ordem pré-colonial ou classista, ou com noções liberais de liberdade ou autonomia ${ }^{6}$. A "complexificação" dos atores do drama colonial para além de grupos homogêneos como colonialistas/colaboradores/ opositores avançada pela antropologia do colonialismo (Cooper; Stoller, 1997) é devedora dessa mudança geral de perspectiva.

Outra solução influente para o problema da agência histórica subalterna é a noção de mimetismo e hibridismo como transgressão proposta por Homi Bhabha (1983; 1985), formulada como contraponto à tendência que ele atribui a Said (de fato, catalisada por Spivak) de presumir que o poder e o discurso pertencem inteiramente ao colonizador ${ }^{7}$. Para Bhabha, a fixidez não dialógica seria um atributo ideológico do poder colonial, ou seja, parte da sua autoimagem oficial, cuja finalidade seria mascarar múltiplas contradições oficiosas. O mimetismo do colonizado paradoxalmente expõe essas contradições, transfigurando-se assim em "momentos de desobediência civil no interior da disciplina da 'civilidade': sinais espetaculares de resistência" (Bhabha, 1985, p. 162), que transformam um espaço de purificação 
em um espaço de hibridização - veja-se exemplos em, Burke (1996), Comaroff e Comaroff ( 1997) ${ }^{8}$. Apesar de evitar noções como "hibridismo", Asad (neste volume) parte de pressupostos similares quando rejeita a tese da antropologia como simples reflexo da ideologia colonial, não

[...] porque concorde com a visão de si confortável do establishment antropológico, mas porque a consciência burguesa, da qual a antropologia é apenas um fragmento, sempre conteve dentro de si profundas contradições e ambiguidades - e logo também a possiblidade de transcender a si mesma.

Uma última dimensão dessa questão que gostaríamos de destacar foi articulada mais recentemente por Dipesh Chakrabarty (2000): como pensar a agência subalterna para além dos protocolos seculares? Referindo-se ao esvaziamento marxista-secularista do mundo espiritual camponês operado pelos estudos subalternos, Chakrabarty (2000, p. 88) argumenta:

[...] precisamos formular críticas de instituições em seus próprios termos, críticas seculares para instituições seculares de governo. O pensamento de Marx, ainda a mais poderosa crítica secular do capital, permanece indispensável para o nosso engajamento com a questão da justiça social em sociedades capitalistas. Mas meu ponto é que o indispensável permanece inadequado, pois ainda temos de traduzir para o tempo da "História" e para a narrativa secular e universal do "trabalho" estórias sobre seres humanos que incorporaram a agência de deuses e espíritos.

Parece haver um paradoxo incontornável no projeto metodológicopolítico de se resgatar a agência histórica de coletivos que, por sua vez, insistem em dissolver ou redistribuir a sua própria agência em modos "antissociológicos" (Chakrabarty, 2000, p. 88) de temporalização. Esse é de fato um procedimento típico do discurso anticolonial. Para Fanon (1979, p. 41), por exemplo, a "religião" opera no contexto colonial, sobretudo, como um meio de acomodação via fatalismo, em que "toda a iniciativa é arrebatada ao opressor, atribuindo-se a Deus as causas dos males, da miséria, do destino". Sua abordagem para "o plano fantasmagórico" ou a "superestrutura mágica" do colonialismo em 
África - a proliferação de "gênios malfazejos", "homens-leopardos", "homens serpentes", "cachorros de seis patas", "zumbis" - circunscreve esses fenômenos como frutos das patologias geradas pelo colonialismo na psique colonizada, modos através do quais o colonizado extrai "inibições para a sua agressividade" (Fanon, 1979, p. 41). Possessões, por sua vez, operam, para ele, como "dissoluções motoras da crise" (Fanon, 1979, p. 42). Não por acaso, Fanon (1979, p. 43) erra redondamente ao profetizar que a luta pela libertação nacional geraria na África "um singular desapego por essa práticas" ( Lan, 1985, Comaroff; Comaroff, 1993; Geschiere, 1997).

O problema apontado por Chakrabarty tem sido de fato explorado pela antropologia de modo mais refinado ao longo dos anos. Michael Taussig (1987), por exemplo, utiliza-se da crítica de Walter Benjamin do historicismo burguês para reinserir de forma produtiva e com grande destreza poética a "fantasmagoria colonial" em processos de temporalização, cura e crítica cultural na América Latina. Na mesma época, Aiwha Ong (1987) trabalhou o elemento de gênero e sexualidade em sua etnografia sobre possessão por espíritos entre jovens operárias na Malásia, durante a rápida transformação do país de sociedade rural em um dos tigres asiáticos do capitalismo tardio.

Talal Asad tem se dedicado desde os anos 1980 à genealogia da categoria universal de "religião" e aos protocolos normativos de sua associação antropológica (e Protestante) com a "crença", o "simbolismo" e o "ritual" (Asad, 1993). Esse projeto passa pelo estudo histórico de como a "religião" enquanto modo de tradução e governo da diferença ampliou seu escopo em meio a redes imperiais (Chidester, 1996; Van der Veer, 2001; Masuzawa, 2005), e deságua na proposição simétrica de Asad de uma antropologia da religião e do secularismo enquanto "gêmeos siameses" (Asad, 2003; Agrama, 2012; Mahmood, 2016; Hirschkind, 2017). É cada vez mais urgente entre antropólogos a sensibilidade de que a perspectiva pós-colonial exigiria uma perspectiva pós-secular (Reinhardt, neste volume).

Partindo de uma trajetória distinta, centrada na crítica alternativa da "crença" proposta por Bruno Latour (1991; 2002), a virada ontológica na antropologia tem, mais recentemente, abordado temas similares 
por meio da noção de "cosmopolíticas" (De la Cadena, 2010; Stolze; Lima; 2011; Goldman, 2015) - de certa forma, respondendo àqueles que acusam seu foco unilateral na "autodeterminação ontológica" (Viveiros de Castro, 2015) dos mundos colonizados de esvaziar o político (Ramos, 2012). Uma contribuição singular desse grupo tem sido a sua capacidade de incluir nos debates sobre colonialidade a questão da Natureza, logo também da crise ecológica (Danowski; Viveiros de Castro, 2014, Latour, 2017) ${ }^{9}$. Apesar de fugir ao escopo deste dossiê, esse corpo de trabalhos coloca uma provocação extremamente relevante para nossos interesses: a possiblidade de uma crítica que possa ser qualificada como pós-colonial (já que interessada em provincializar a modernidade hegemônica sob a ótica de sua sombras e pontos cegos) não precisar passar pela seara da teoria pós-colonial aberta por Said, orientada primariamente para o problema da descolonização da representação ${ }^{10}$.

De fato, a pluralidade de influências e ressonâncias que fundamentam a teoria pós-colonial desde a sua origem faz como ela opere de forma sempre dialógica e esquismogênica, como uma "crosstalk" (Slemon, 1994) - seus problemas não raramente excedendo as respostas que ela mesma oferece. Assim, o trabalho pós-colonial de situar e provincializar conhecimentos Ocidentais parece se abrir a intermináveis efeitos de looping, como ilustram as recentes críticas à própria teoria pós-colonial como uma modalidade de pós-modernismo diaspórico nortista, ou como um reflexo do campo acadêmico euroamericano em sua fase multiculturalista (Chibber, 2013, debate em Ferreira, neste volume).

A própria experiência pós-colonial tem escapado a espacializações bem definidas como centro/periferia, Norte/Sul, e suas temporalidades lineares de "progresso" e "atraso" em um contexto neoliberal onde nações do Sul alcançaram grande protagonismo no capitalismo global, e onde a Europa, suposto centro do cosmopolitismo moderno, se engalfinha com o problema da autoctonia, das fronteiras e da etnicidade (Geschiere, 2009; Comaroff; Comaroff, 2012). Em seu trabalho seminal, David Scott (1999, p. 18) já apontara para a necessidade de avançarmos para um terceiro momento e "espaço-problema", que ele chama de "depois da pós-colonialidade", dada a necessidade de se "desdobrar 
a política da teoria que tem caracterizado a pós-colonialidade em uma nova teoria do político". Isso se dá em meio a uma nova onda global de neutralização técnica e pragmática da história e do político (Ferguson, 1990; Mkandawire; Soludo, 1999; Harvey, 2008), indicando que "[...] o colapso do estilo soviético de comunismo e a ressurgência do neoliberalismo altera o contexto cognitivo-político em que a crítica póscolonial pode operar, e portando as próprias demandas que mobilizam a crítica" (Scott, 1999, p. 136. ${ }^{11}$.

\section{O Pós-Colonial na Antropologia Brasileira}

No Brasil, autores e obras da literatura pós-colonial têm sido introduzidos de modo crescente nas ciências sociais a partir dos anos 2000 (Costa, 2006). Não obstante, esforços criativos de reler clássicos do pensamento social brasileiro como pioneiros de uma visada pós-colonial, como Euclides da Cunha (Maia, 2010), Guerreiro Ramos (Lynch, 2015), Darcy Ribeiro (Miglievich-Ribeiro, 2011 ) e até mesmo Gilberto Freyre (Melo, 2014), as principais referências têm vindo majoritariamente da literatura internacional. Discussões bibliográfico-teóricas pioneiras na antropologia (Carvalho, 2001; Cunha, 2002; Machado, 2004,) apontam, além dos clássicos Edward Said e Frantz Fanon, para autores ligados aos subaltern studies e cultural studies como Homi Bhabha, Gayatri Spivak, Stuart Hall e Paul Gilroy, além de antropólogos diretamente engajados nesses debates como Arjun Appadurai e Lila Abu-Lughod. Alguns subcampos da antropologia têm se sobressaído neste diálogo, como relações raciais e interétnicas (Pinho, 2010; Lewis, 2014), gênero e feminismo (Segato, 2012b; López, 2015) e educação (Oliveira, 2014).

É interessante notar como, não obstante o interesse teórico crescente pela questão e literatura pós-coloniais na antropologia brasileira, ainda são poucos os estudos de base empírica que operam através dessa inspiração analítica. A título de organização geral do campo, poderíamos diferenciar entre os estudos antropológicos de inspiração pós-colonial, feitos a partir do Brasil, e sobre o Brasil. No primeiro caso, estão antropólogos que têm trabalhado em contextos etnográficos diferentes do brasileiro, particularmente aqueles historicamente ligados ao próprio desenvolvimento da teoria pós- 
colonial. Entre estes, destacam-se África (Bastos et al., 2002; Leite, 2007; Marcon, 2013; Reinhardt neste volume), Caribe (Handerson, 2015; Brittes, neste volume), a Índia e sua diáspora (Hofbauer, 2015; Ferreira, neste volume) e o sudeste asiático, em especial seu enclave lusófono, o Timor Leste (Costa, neste volume).

No caso dos trabalhos de viés pós-colonial baseados em pesquisas sobre o Brasil, também encontramos um espectro de possibilidades. O Orientalismo de Edward Said tem servido de inspiração para pensar desde os aportes discursivos a processos de colonialismo interno, como o indigenismo (Ramos, 1998) e a "invenção do Nordeste" (Albuquerque Jr., 1999), até visões do Brasil sobre outras partes do mundo (Hamid, 2013) - ou, ainda, a articulação entre os dois (Cesarino, 2017). Outro clássico do campo, Frantz Fanon, vem se tornando referência cada vez mais frequente, em especial (mas não apenas) nos estudos antropológicos sobre raça e populações afro-brasileiras (Pinho, 2010; Ferreira, 2014; Lewis, 2014; López, 2015). É possível encontrar, ainda, recurso a noções avançadas pelos subaltern studies e estudos culturais para pensar temas ligados a identidade, diáspora e a voz subalterna (Zhouri, 2015; Morawska; Vianna, neste volume).

Por fim, é possível identificar esforços emergentes no sentido de pensar quais seriam as particularidades do pós-colonial no caso brasileiro. Esse tipo de reflexão leva a uma aproximação com desdobramentos mais recentes e específicos do campo, notadamente o giro decolonial latino-americano e a literatura sobre o pós-colonialismo lusófono. No primeiro caso, autores como Aníbal Quijano, Walter Mignolo e Arturo Escobar não só têm sido cada vez mais referenciados (Velho, 2010; Segato, 2013; Ferreira, 2014, Cesarino, neste volume), como alguns deles têm entretido interlocução direta com a antropologia brasileira por meio de autores tão diferentes como Rita Segato e Gustavo Lins Ribeiro. Já a segunda literatura situa ${ }^{12}$ a experiência pós-colonial brasileira em termos menos da América Latina do que do colonialismo português e sua herança no Brasil, África e Ásia. Este eixo de diálogo ainda é bastante incipiente na antropologia brasileira, concentrando-se em temáticas ligadas à lusofonia e às relações do Brasil com outras partes do mundo colonizadas por Portugal (Bastos et al., 2002; Cesarino, 2012; 2017; Costa, neste volume). 


\section{Este Dossiê}

Este dossiê pretende contribuir para a expansão e sistematização dos diálogos emergentes entre antropologia e o campo pós-colonial no Brasil. Pelos motivos elencados nesta apresentação, e dando continuidade ao espírito antidogmático que autores como Said ajudaram a estimular em nossa disciplina, julga-se prudente desvincular a crítica pós-colonial da teoria pós-colonial, entendendo a última como apenas uma modalidade possível da primeira. Os artigos a seguir exploram algumas vias de diálogo - seja como mútua problematização ou fertilização - entre a antropologia e a crítica pós-colonial, refletindo uma ampla variedade de abordagens para o tema desenvolvidas por meio de engajamentos etnográficos e teóricos realizados em contextos diversos: Brasil (Cesarino, Morawska Vianna), Timor Leste (Costa), Suriname (Brittes), Gana (Reinhardt), Índia (Hofbauer) e Inglaterra (Ferreira).

As contribuições de Andreas Hofbauer e Letícia Cesarino têm um caráter metateórico mais explícito, explorando os des/encontros entre a antropologia e literatura pós-colonial a partir de preocupações com contextos específicos - Índia e Brasil, respectivamente. No artigo de Cesarino, o pós-colonial opera como um mecanismo de recontextualização e reconfiguração, nos termos de preocupações contemporâneas, de uma noção clássica nas ciências sociais: a de colonialismo interno. A produtividade dessa reconfiguração (como colonialidade interna) é defendida por meio de uma retomada do tema da mestiçagem como identidade nacional no Brasil através de um viés pós-colonial. Pensar a mestiçagem como discurso hegemônico implica, neste caso, visibilizar o papel da gramática culturalista consolidada por Gilberto Freyre enquanto código privilegiado através do qual grupos subalternizados pela colonialidade interna brasileira têm sido seletivamente reconhecidos e incorporados no corpo político nacional. Aqui, também, "todo documento de cultura é também um documento de barbárie", e na medida em que a antropologia é, em uma de suas principais versões, a ciência da cultura, o artigo desafia a disciplina no Brasil a enfrentar o tipo de reflexividade que a crítica pós-colonial (tanto interna quanto externa) havia suscitado no caso das antropologias 
centrais.

Já a contribuição de Hofbauer explora um outro problema em comum entre a antropologia e a literatura de viés pós-colonial: o das classificações simbólicas e fronteiras identitárias. Após apresentar uma discussão densa e ampla de contrastes fundamentais e acusações mútuas entre os dois campos, o autor busca uma posição a meio caminho, que contemple tanto o foco etnográfico nos "hábitos, valores e cosmovisões locais" e os jogos de poder gerados a partir das "imposições coloniais". Partindo de sua pesquisa atual sobre os siddis (afrodescendentes) na Índia, Hofbauer desenvolve essa articulação por meio de duas interpretações seminais, e aparentemente conflitantes, sobre o sistema de castas - dos antropólogos Susan Bayly e Nicholas Dirks. Ele busca evidenciar como, longe de serem interpretações excludentes, a visão antropológica "clássica" e aquela que incorpora a crítica pós-colonial trazem focos distintos, porém complementares, enriquecendo assim a nossa perspectiva ao permitir "operarmos em mais de um plano analítico simultaneamente" por meio da construção de "cenários multifacetados".

Daniel De Lucca Costa desloca o foco etnográfico ainda mais para o leste, para um contexto que vem sendo cada vez mais palco de pesquisas antropológicas brasileiras: o Timor-Leste. Por meio de uma análise das celebrações dos "500 anos" deste que é um dos estadosnação mais recentes do mundo, o autor discute as tensões entre as múltiplas camadas históricas que compõem a complexa temporalidade pós-colonial timorense. A celebração de "dois momentos aparentemente contraditórios, a gênese do laço colonial [com os "descobrimentos" portugueses] e sua ruptura [através da independência em 1975], problematiza a inserção daquele país no espaço-tempo lusófono - ao mesmo tempo em que evidencia, como em Cesarino (neste volume), que tais contradições são, ao mesmo, algo constitutivo da experiência (pós)colonial portuguesa, e talvez do momento contemporâneo de modo mais geral.

Os artigos de Rogério Brittes, Bruno Reinhardt e Catarina Morawska Vianna também se debruçam sobre o problema da temporalidade, seja em contextos pós-coloniais (no sentido de recente descolonização), como Suriname e Gana, seja pela via da teoria pós-colonial. Os três dialogam 
com o trabalho de Achille Mbembe (2001), e partem do reconhecimento do pluralismo temporal que caracteriza a vida nos ambientes etnográficos em que suas pesquisas se desenrolam, tornando-a flagrantemente opaca a oposições binárias entre temporalidades autóctones/exógenas e éticas da continuidade/mudança. Essa situação leva seus trabalhos a evocar e explorar propriedades não lineares do tempo, como a reversibilidade, a assincronia, o emaranhamento polifônico e a virtualidade.

Brittes reflete sobre a temporalidade dos Saamaka, uma população maroon do Suriname, cujos hábitos linguísticos articulam o futuro "atrás" e o passado "na frente", logo de maneira incongruente com a línguas indo-europeias. Esse fenômeno testemunha para a historicidade particular de um povo descendente de escravizados, logo gestado nas margens do projeto imperial europeu. Brittes explora em detalhes as relações entre a temporalidade reversa dos Saamaka e a teleologia capitalista do "progresso" por meio da noção ética e politicamente densa de "tradição" proposta por David Scott em artigo traduzido por ele e Julia Sauma para este volume.

Reinhardt investiga alguns modos Pentecostais de habitar o verdadeiro vórtice temporal aberto pelo ocaso das temporalidades seculares redentoras em Gana desde a sua descolonização. Seu foco etnográfico recai sobre a prática de "espera por Deus" em retiros de oração e o estilo de vida de um evangelista popular, ambos os fenômenos sendo apresentados como modos polifônicos de navegação temporal por um contexto em que "crise" refere-se não mais a um evento de ruptura, mas a um horizonte temporal paradoxal, já que continuamente contingente.

Morawska Vianna lida com o problema da temporalidade através de diversas escalas textualmente concatenadas: as teorias antropológica e pós-colonial e as histórias de vida de seus sujeitos de pesquisa, educadores populares cujo engajamento com o aparato não governamental do desenvolvimento é mediado por novos modos de relatos-de-si orientados por marcadores de diferença como raça, gênero, sexualidade e cultura. A noção de "bifurcação" (Strathern, 2011 ) é proposta como uma solução etnograficamente embasada para possíveis impasses que emergem entre as perspectivas antropológica e pós-colonial. 
O artigo de Vinícius Kauê Ferreira é igualmente reflexivo e multiescalar e aborda a teoria pós-colonial como um campo simultaneamente conceitual, pessoal, e profissional ao traçar as tensões e disputas sobre pertencimento que constituem as carreiras de cientistas sociais de origem indiana na Inglaterra. Assim como muitos intelectuais deste campo - como Fanon, Said, Spivak, Hall e outros - as vidas e obras de seus interlocutores são predicadas em modos de habitação em redes imperiais. Ferreira traça as forças contraditórias que se intercalam durante este processo, como a valorização mercadológica de intelectuais indianos por sua exposure e a ossificação de suas vozes e carreiras em torno de seus locais de descendência ou a participação cosmopolita em redes transnacionais e a discordâncias com outras vertentes diaspóricas, como o nacionalismo Hindu.

Cada um dos artigos que compõem este dossiê representa um modo particular de conceber e de mobilizar analiticamente a noção de crítica pós-colonial, refletindo a natureza exploratória deste projeto. Não houve tentativa, por parte dos editores, de homogeneizar visões e abordagens sobre o tema, já que consideramos nosso principal objetivo reconhecer a sua importância enquanto uma problemática, e não como um campo ou escola teórica, nitidamente discerníveis da prática antropológica.

\section{Notas}

1 Doutor em Antropologia pela Universidade da Califórnia, em Berkeley. Pesquisador pós-doc filiado ao Programa de Pós-graduação em Antropologia Social da Universidade Federal de Santa Catarina.

2 Professora do Departamento de Antropologia e Programa de Pós-Graduação em Antropologia Social (PPGAS) da Universidade Federal de Santa Catarina (UFSC).

3 Em entrevista a David Scott, Asad comenta que Anthropology and the Colonial Encounter teve uma recepção pobre na Inglaterra, tendo sido lido primariamente "como um ataque pessoal" (Hirschkind; Scott, 2006, p. 261).

4 Reações igualmente defensivas foram endereçadas a outro projeto crítico publicado na mesma época do outro lado do Atlântico, Reinventing Anthropology, organizado por Dell Hymes (1972)(Leach, 1974).

5 Talal Asad participou deste volume com um capítulo sobre a noção de "tradução" na antropologia britânica e o que ele chama de "a desigualdade das línguas", que estruturaria esse processo.

6 Evitando assim a postura caricatural de Sahlins (2004) sobre este debate.

7 Vale lembrar que o próprio Said eventualmente revisita a questão da resistência em sua obra (Said, 1985; 1993). 
8 A tendência da pedagogia colonial da "civilização" de operar não em detrimento, mas através de uma série de double-binds, uma lógica que incitava constantemente a imitação do sujeito ocidental enquanto rejeitava a autenticidade das cópias colonizadas que produzia, faz com que Achille Mbembe qualifique o poder colonial como "o poder do falso" (2010: 15). James Ferguson (2006, p. 155-175), por sua vez, critica as abordagens generalistas para o mimetismo como transgressão inspiradas em Bhabha, reclamando uma abordagem mais etnograficamente situada para a relação ente imitação, reconhecimento e pertencimento.

9 O divisor natureza-cultura também tem sido trabalhado, embora de modo incipiente e bastante heterogêneo, nos recentes esforços de cruzamento entre os science and technology studies e questões pós-coloniais (Harding, 2011; Law; Lin, 2017).

${ }^{10}$ Esse debate continua, e autores como Bessire e Bond (2014) duvidam da possibilidade desse descolamento.

${ }^{11}$ No Brasil, essa contradição tem se observado, por exemplo, na simultaneidade entre a consolidação de políticas de ação afirmativa nas universidades e seus efeitos emergentes no meio acadêmico, e a reintensificação do projeto neoliberal de solapamento do caráter público dessas mesmas universidades.

12 Em um artigo seminal para a discussão do pós-colonial lusófono, Boaventura de Sousa Santos (2003, p. 29) avança a proposta de "pós-colonialismos situados", que impliquem "cuidadosas análises históricas e comparadas dos colonialismos e do que se lhes seguiu. É crucial responder à pergunta sobre quem descoloniza o que e como".

\section{Referências}

ACHEBE, Chinua. Hopes and Impediments: Selected Essays 1965-1987 London: Heinemann, 1988.

AGRAMA, Hussein. Questioning Secularism: Islam, Sovereignty, and the Rule of Law in Modern Egypt. Chicago; London: The University of Chicago Press, 2012.

ASAD, Talal (Org.). Anthropology and the Colonial Encounter. Front Cover. Ithaca Press, 1973

. Two European images of two non-European rules. In: ASAD, Talal (Org.). Anthropology and the colonial encounter. London: Ithaca Press, 1973b. p. 103-20

. Genealogies of Religion: Discipline and Reasons of Power in Christianity and Islam. Baltimore: The Johns Hopkins University Press, 1993.

Formations of the Secular: Christianity, Islam, Modernity: Stanford: Stanford University Press, 2003.

BASTOS, Cristiana Miguel Vale de Almeida; feldman-bianco, Bela (Org.), Trânsitos Coloniais: Diálogos Críticos Luso-Brasileiros, Lisboa: Imprensa de Ciências Sociais, 2002. 
BESSIRE, Lucas; BOND, David. Ontological Anthropology and the Deferral of Critique. American Ethnologist, [S.l.], v. 41, n. 3, p. 440-456, 2014.

BHABHA, Homi. The Other Question... Screen, [S.l.], v. 24, n. 6, p. 18-36, 1983.

. Signs Taken for Wonders: Questions of Ambivalence and Authority under a Tree outside Delhi, May 1817. Critical Inquiry, [S.l.], v. 12, n. 1, p. 144-165, 1985.

BISHOP, Alan. Western Mathematics: The Secret Weapon of Cultural Imperialism. Race \& Class Race \& Class, [S.l.], v. 32, n. 2, p. 51-65, 1990.

BURKE, Timothy. Lifebuoy Men, Lux Women: Commodification, Consumption, and Cleanliness in Modern Zimbabwe. Durham: Duke University Press, 1996.

CARVALHO, José Jorge de. O Olhar Etnográfico e a Voz Subalterna. Horizontes Antropológicos, [S.l.], v. 7, n. 15, p. 107-147, 2001.

CESARINO, Letícia. Brazilian Postcoloniality and South-South Cooperation: A View from Anthropology. Portuguese Cultural Studies, [S.l.], v. 4, n. 1, p. 85-113, 2012.

. Anthropology and the South-South Encounter: On "Culture" in Brazil-Africa Relations. American Anthropologist, [S.l.], v. 119, n. 2, p. 333-341, 2017.

CLIFFORD, James. Review of Orientalism, by Edward Said. History and Theory, [S.l.], v. 12, n. 2, p. 204-223, 1980.

CLIFFORD, James; MARCUS, George. Writing culture: the poetics and politics of ethnography. Berkeley: University of California Press, 1986.

CHAKRABARTY, Dipesh. Provincializing Europe: Postcolonial Thought and Historical Difference. Princeton: Princeton University Press, 2000.

CHIBBER, Vivek. Postcolonial Theory and the Specter of Capital. London: Verso, 2013.

CHIDESTER, David. Savage Systems: Colonialism and Comparative Religion in Southern Africa. Charlottesville: University Press of Virginia, 1996.

COMAROFF, Jean; COMAROFF, John. Of Revelation and Revolution, Vol 1: Christianity, Colonialism, and Consciousness in South Africa. Chicago: Chicago University Press, 1991.

. Modernity and Its Malcontents: Ritual and Power in

Postcolonial Africa. Chicago: Chicago University Press, 1993. 
. Of Revelation and Revolution, Vol. 2: The Dialectics of Modernity on a South African Frontier. Chicago: University of Chicago Press, 1997.

\section{. Theory from the South or, How Euro-America Is Evolving}

toward Africa. Boulder: Paradigm Publishers, 2012.

COOPER, Frederick; STOLER, Ann Laura. Tensions of Empire: Colonial Cultures in a Bourgeois World. Berkeley: University of California Press, 1997.

COSTA, Sergio. Desprovincializando a sociologia: a contribuição póscolonial. Revista Brasileira de Ciências Sociais, [S.l.], v. 21, n. 60, p. 117-134, 2006.

CUNHA, Olivia. Reflexões sobre biopoder e colonialismo: relendo Fanon e Foucault. Mana, Rio de Janeiro, v. 8, n. 1, p. 149-163, 2002.

DANOWSKI, Déborah; VIVEIROS DE CASTRO, Eduardo. Há mundo por vir? Ensaio sobre os medos e os fins. Florianópolis: Cultura e Barbárie; Instituto Socioambiental, 2014.

DE LA CADENA, Marisol. Ingigenous cosmopolitics in the Andes: Conceptual Reflections beyond "Politics". Cultural Anthropology, [S.l.], v. 25, n. 2, p. 334-370, 2010.

DIRKS, Nicholas (Org.). Colonialism and Culture. Ann Harbor: Michigan University Press. 1992.

ESCOBAR, Arturo. Worlds and knowledges otherwise: the ModernityColoniality Research Program. Cultural Studies, [S.l.], v. 21, v. 2-3, p. 179210, 2007.

FABIAN, Johannes. O tempo e o outro: como a antropologia estabelece seus objetos. Petrópolis: Vozes, [1983] 2013.

FANON, Frantz. Pele Negra Máscaras Brancas. Salvador: EDUFBA, [1952] 2008. [1961] 1979 .

Os Condenados da Terra. Rio de Janeiro: Civilização Brasileira.

FERGUSON, James. The Anti-Politics Machine: "development", depoliticization, and bureaucratic power in Lesotho. University of Minnesota Press, 1990.

Global shadows: Africa in the neoliberal world order. Durham:

Duke University Press, 2006. 
FERREIRA, Andrey. Colonialismo, capitalismo e segmentaridade: nacionalismo e internacionalismo na teoria e política anticolonial e póscolonial. Sociedade e Estado, [S.l.], v. 29, n. 1, p. 255-288, 2014.

GELLNER, Ernest. In defence of Orientalism. Sociology, [S.l.], v. 14, n. 2, p. 295-300, 1980.

GERHOLM, Tomas; HANNERZ, Ulf. Introduction: The shaping of national anthropologies. Ethnos, [S.l.], v. 1-2, p. 5-35, 1982.

GESCHIERE, Peter. The Modernity of Witchcraft: Politics and the Occult in Postcolonial Africa. Charlottesville: University of Virginia Press, 1997.

. The Perils of Belonging: Autochthony, Citizenship, and Exclusion in Africa and Europe. Chicago: University of Chicago Press, 2009.

GLUCKMAN, Max. "Report from the Field. Letter to the Editors". New York Review of Books, [S.l.], v. 28, n.11, p. 43-44, 1974.

GOLDMAN, Márcio. Quinhentos anos de contato: por uma teoria etnográfica da (contra)mestiçagem. Mana, [S.l.], v. 21, n. 3, p. 641-659, 2015.

HAMID, Sônia. O reassentamento de palestinos no Brasil: discursos orientalistas de gênero. In: $10^{\circ}$ SEMINÁRIO INTERNACIONAL FAZENDO GÊNERO, Florianópolis, 2013. Anais Eletrônico... Florianópolis, 2013. Disponível em: <http://www.fg2013.wwc2017.eventos.dype.com.br/ resources/anais/20/1382029810_ARQUIVO_Hamid,Sonia-GT54.pdf > . Acesso em 22 nov. 2017.

HANDERSON, Joseph. Diásporas negras no contexto pós-colonial: dialogando com intelectuais haitianos. Educere et Educare - Revista de Educação, [S.l.], v. 10, n. 20, p. 537-548, 2015.

HARDING, Sandra (Ed.). The Postcolonial Science and Technology Studies Reader. Durham: Duke University Press, 2011.

HARAWAY, Donna. Situated Knowledges: The Science Question in Feminism and the Privilege of Partial Perspective. Feminist Studies, [S.l.], v. 14, n. 3, p. 575-599, 1988.

HARVEY, David. O Neoliberalismo: história e implicações. São Paulo: Edições Loyola, 2008.

HIRSCHKIND, Charles. Existe um Corpo Secular? Religião e Sociedade, [S.l.], v. 37, n.1, p. 175-189, 2017.

HIRSCHKIND, Charles; SCOTT, David. Powers of the Secular Modern: Talal Asad and His Interlocutors. Stanford: Stanford University Press, 2006. 
HOFBAUER, Andreas. Racismo na Índia? Cor, raça e casta em contexto. Revista Brasileira de Ciência Política, [S.l.], v. 16, p. 153-191, 2015.

KUPER, Adam. Anthropology and Anthropologists: The Modern British School. London: Routledge. 1985.

LAN, David. 1985. Guns \& Rain: Guerrillas \& Spirit Mediums in Zimbabwe. London: James Currey.

LATOUR, Bruno. Jamais fomos modernos: ensaio de antropologia simétrica. Rio de Janeiro: Editora 34, 1991.

Reflexão sobre o culto moderno dos deuses fe(i)tiches. Bauru: EDUSC, 2002.

Facing Gaia: Eight Lectures on the New Climatic Regime, London: Polity Press, 2017.

LAW, John; WEN-YUAN, Lin. Provincializing STS: postcoloniality, symmetry, and method. East Asian Science. Technology and Society: an International Journal, [S.l.], v. 11, p. 1-17, 2017.

LEACH, Edmund. Anthropology Upside Down. Review of Hymes, New York Review of Books, New York, p. 33-35, 1974.

LEITE, Ilka B. Olhares de África: lugares e entre-lugares da arte na diáspora. Tomo: Revista do Núcleo de Pós-Graduação e Pesquisa em Ciências Sociais, Sergipe, Universidade Federal de Sergipe, v. 11, p. 59-75.

LEWIS, Liana. Raça e uma nova forma de analisar o imaginário da nossa comunidade nação: da miscigenação freyreana ao dualismo fanoniano. Civitas, [S.l.], v. 14, v. 1, p. el-el0, 2014.

LIMA, Tânia Stolze. Por uma cartografia do poder e da diferença nas cosmopolíticas ameríndias. Revista de Antropologia, [S.l.], v. 54, n. 2, p. 601-646, 2011.

LOIZOS, Peter. Personal Evidence: Comments on an Acrimonious Debate. Anthropological Forum, [S.l.], v. 4, p. 137-44, 1977.

LÓPEZ, Laura C. O corpo colonial e as políticas e poéticas da diáspora para compreender as mobilizações afro-latino-americanas. Horizontes Antropológicos, [S.l.], v. 43, p. 301-330, 2015.

LYNCH, Christian. Teoria pós-colonial e pensamento brasileiro na obra de Guerreiro Ramos: o pensamento sociológico (1953-1955). Caderno CRH, [S.l.], v. 28, n. 73, p. 27-44, 2015.

MACHADO, Igor Renó. Reflexões sobre o pós-colonialismo. Teoria e Pesquisa, [S.l.], v. 44-45, p. 19-32, 2004. 
MAIA, João Marcelo. O pensamento social brasileiro e a imaginação póscolonial. Revista Estudos Empíricos, [S.l.], v. 0, p. 64-76, 2010.

MAHMOOD, Saba. Politics of Piety: The Islamic Revival and the Feminist Subject. Princeton, N.J.: Princeton University Press, 2005.

. Religious Difference in a Secular Age: A Minority Report.

Princeton: Princeton University Press, 2015.

MAMDANI, Mahmood. Citizen and subject: contemporary Africa and the legacy of late colonialism. Princeton: University Press, 1996.

MANI, Lata. Contentious Traditions: The Debate on Sati in Colonial India. Berkeley: University of California Press, 1998.

MARCON, Frank. O kuduro como expressão da juventude em Portugal: estilos de vida e processos de identificação. Sociedade e Estado, [S.l.], v. 28, n 1, p. 75-90, 2013.

MARCUS, George; FISCHER, Michael. Anthropology as cultural critique: an experimental moment in the human sciences. Chicago: University of Chicago Press, 1986.

MASUZAWA, Tomoko. The Invention of World Religions, or, How European Universalism Was Preserved in the Language of Pluralism. Chicago: University of Chicago Press, 2005.

MBEMBE, Achille. On the Postcolony. Berkeley: University of California Press., 2001.

Sortir de La Grande Nuit: Essai Sur l'Afrique Décolonisée. Paris: La Découverte. 2010.

MELO, Alfredo Cesar. Hibridismos (in)domáveis: possíveis contribuições da obra de Gilberto Freyre para uma teoria pós-colonial lusófona. LusoBrazilian Review, [S.l.], v. 51, n. 1, p. 68-92, 2014.

MEMMI, Albert. The colonizer and the colonized. New York: Beacon Press, [1957] 1965.

MIGLIEVICH-RIBEIRO, Adelia. A crítica pós-colonial a partir de Darcy Ribeiro: uma releitura de o povo brasileiro. Revista de Estudos Antiutilitaristas e Poscoloniais, [S.l.], v. 1, n. 1, p. 134-146, 2011. MIGNOLO, Walter. Local histories/ Global designs: Coloniality, Subaltern Knowledges, and Border Thinking. New Jersey: Princeton University Press, 2000.

. Coloniality at Large: The Western Hemisphere in the Colonial Horizon of Modernity. The New Centennial Review, [S.l.], v. 1, n. 2, p. 19-54, 2001. 
MINTZ, Sidney. Sweetness and Power: The Place of Sugar in Modern History. New York: Penguin Books, 1987.

MITCHELL, Timothy. Colonizing Egypt. Berkeley: University of California Press, 1991.

MKANDAWIRE, Thandika; SOLUDO, Charles. Our Continent, Our Future: African Perspectives On Structural Adjustment. Dakar: Council For The Development Of Social Science Research In Africa, 1999.

MOHANTY, Chandra. Under Western Eyes: Feminist Scholarship and Colonial Discourses. Boundary, [S.l.], v. 2, p. 333-358, 1984.

MUDIMBE, Valentin. The Invention of Africa: gnosis, philosophy, and the order of knowledge. Bloomington: Indiana Univ. Press, 1988.

OLIVEIRA, Amurabi. Antropologia, colonialidade e pós-colonialidade: diálogos possíveis com a educação. Quaesito, [S.l.], v. 16, n. 1, p. 11-23, 2014.

ONG, Aiwha. Spirits of Resistance and Capitalist Discipline: factory women in Malaysia. Albany: SUNY Press, 1987.

PEIRANO, Mariza. Uma antropologia no plural: três experiências contemporâneas. Brasilia: Editora UnB, 1991.

. When anthropology is at home: The Different Contexts of a Single Discipline. Annual Review of Anthropology, [S.l.], v. 27, p. 105-128, 1998.

PELS, Peter. The Anthropology of Colonialism: Culture, History and the Emergence of Western Governmentality. Annual Review of Anthropology, [S.l.], v. 26, p.163-183, 1997.

PELS, Peter; SALEMINK, Oscar. Introduction: Five Theses on Ethnography as Colonial. Practice History and anthropology, [S.l.], v. 8, n. 1-4, p. 1-34, 1994.

PINHO, Osmundo. O mundo negro: hermenêutica da reafricanização em Salvador. Curitiba: Progressiva, 2010.

QUIJANO, Anibal. Colonialidade do poder, Eurocentrismo e America Latina. In: LANDER, Edgardo. (Org.). A Colonialidade do Saber: eurocentrismo e ciências sociais. Perspectivas Latino-americanas. Buenos Aires: CLACSO, 2005. p. 105-127.

RABINOW, Paul. Antropologia da Razão. Rio de Janeiro: Relume Dumará, 1999.

RAMOS, Alcida Rita. Indigenism: Ethnic Politics in Brazil. Madison: University of Wisconsin Press, 1998. 
. The Politics of Perspectivism. Annual Review of Anthropology,

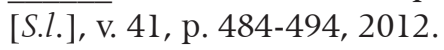

REINHARDT, Bruno. Poder, História e Coetaneidade: os Lugares do Colonialismo na Antropologia sobre a África. Revista de Antropologia, [S.l.], v. 57, n. 2, p. 329-275, 2014.

RIBEIRO, Gustavo Lins; ESCOBAR, Arturo (Org.). World

Anthropologies: Disciplinary Transformations in Systems of Power.

Oxford: Berg, 2006.

SAHLINS, Marshall. Esperando Foucault, ainda. São Paulo: Cosac Naify, 2004.

SAID, Edward. Orientalism. New York: Penguin. [1978] 2006.

. Orientalism Reconsidered, Race and Class, v. 27, p. 1-15. 1985

. Culture and Imperialism. New York: Knopf, 1993.

SANTOS, Boaventura de Sousa. Entre Próspero e Caliban: colonialismo, pós-colonialismo e inter-identidade. Novos Estudos, [S.l.], v. 66, p. 23-52, 2003.

SEGATO, Rita Laura. Brechas descoloniales para una universidad nuestroamericana. Revista Casa de las Américas, [S.l.], n. 266, p. 43-60, 2012a.

. Gênero e colonialidade: em busca de chaves de leitura e de um vocabulário estratégico descolonial. E-cadernos CES, [S.l.], v. 18, p. 106131, 2012b.

. La crítica de la colonialidad en ocho ensayos y una

antropologia por demanda. Buenos Aires: Prometeo Líbros, 2013.

SLEMON, Stephen. The Scramble for Postcolonialism. In. TIFFIN, Chris; LAWSON, Alan. (Org.). De-Scribing Empire: Post-Colonialism and Textuality. New York: Routledge, 1994. p. 15-30.

SPIVAK, Gyatri. Can the Subaltern Speak? Speculations on WidowSacrifice. Wedge, [S.l.], v. 7/8, p. 120-130, 1985.

STOCKING, George. Race, Culture, and Evolution: Essays in the History of Anthropology. Chicago: Univ. of Chicago Press, 1968.

STOCKING Jr., George. Afterword: a view from the center. Ethnos, [S.l.], v. 47, p. 172-186, 1982.

STRATHERN. Marilyn. Binary License. Common Knowledge, [S.l.], v. 17, n. 1, p. 87-103, 2011. 
TAUSSIG, Michael. Shamanism, Colonialism, and the Wild Man: A Study in Terror and Healing. Chicago: University of Chicago Press, 1987.

VAN DER VEER, Peter. Imperial Encounters: Religion and Modernity in India and Britain. Princeton: Princeton University Press, 2001.

VELHO, Otávio. O que nos une. Anuário Antropológico, [S.l.], v. II, p. 9-21, 2010.

VISWANATHAN, Gauri. Masks of Conquest: Literary Study and British Rule in India. New York: Columbia University Press, 1989.

VIVEIROS DE CASTRO, Eduardo. Metafísicas Canibais. São Paulo: Cosac Naify, 2015.

WOLF, Eric. Europe and the People without History. Berkeley: University of California Press, 1982.

ZHOURI, Andrea. From 'participation' to 'negotiation': suppressing dissent in environmental conflict resolution in Brazil. In: BRIANT, Raymond (Org.). The International Handbook of Political Ecology. Chentelham, UK: Edward Elgar, 2015. p. 447-459. 